\title{
FORMULASI LULUR KRIM YANG MENGANDUNG KOMBINASI YOGHURT DAN PATI BERAS HITAM (Oryza sativa L.)
}

\author{
Vina Purnamasari $\mathbf{M}^{1}$, Ermina Pakki ${ }^{2}$, Mirawati ${ }^{1}$ \\ ${ }^{1}$ Fakultas Farmasi Universitas Muslim Indonesia, Makassar \\ ${ }^{2}$ Fakultas Farmasi Universitas Hasanuddin, Makassar \\ Email : vina.dimas29@gmail.com
}

\begin{abstract}
Herbal cream formulation that contain yoghurt and black rice (Oryza sativa L.) combination investigation has been done, used anionik amin soap (stearic acid and triethanolamin), nonionik (tween 80), anionik detergent (Sodium lauryl sulfate) as the emulgator. An investigation purpose was to have a herbal cream formulation most optimum in stability. Stability evaluation performed before and after accelerated condition in $5^{\circ} \mathrm{C}$ and $35^{\circ} \mathrm{C}$ for 10 cycles. Organoleptis, creaming volume, viskositas, emulsion type, homogenitas and dispersed globul then observed. The results showed parameters of organoleptic testing, kriming volume, homogeneity, and the type of emulsion drops dispersed in the ninth formula obtained no change before and after strees conditions. But the viscosity measurements showed formulas that use anionic emulgator such us amin soap (formula I - III) or detergents (Formula VII - IX) results do not change viscosity $(\alpha=5 \%)$ after being kept in conditions that are imposed. So it can be concluded the formula I - III and VII - IX produces a more stable Herbal cream physically.
\end{abstract}

Keywords : Herbal Cream, Yoghurt, Black Rice.

\section{PENDAHULUAN}

Yogurt adalah produk yang diperoleh dari susu sapi yang telah di pasteurisasi, kemudian difermentasi dengan bakteri tertentu (bakteri probiotik Streptococcus thermophilus dan bakteri probiotik Lactobacillus bulgaricus), sampai diperoleh keasaman, bau dan rasa yang khas, dengan atau tanpa penambahan bahan lain yang di izinkan. Salah Satu kandungan yogurt adalah asam laktat dan biotin. ${ }^{1}$ Asam laktat memiliki beberapa khasiat seperti aktivitas antimikroba, mencerahkan kulit, dan hidrasi kulit. $^{2}$

Beras hitam memiliki pigmen antosianin yang berperan sebagai antioksidan. Kandungan antosianin 
Formulasi Lulur Krim Yang Mengandung Kombinasi Yoghurt Dan Pati Beras Hitam ( sativa L.)

total pada beras hitam berkisar antara $159,31-359,51 \mathrm{mg} / \mathrm{lOO} \mathrm{g.}{ }^{3}$

Kombinasi antara yogurt dan beras hitam sebagai scrub dapat diformulasi dalam bentuk sediaan lulur krim. Sediaan lulur krim dipilih karena bentuk sediaan tersebut lebih efektif, praktis, dan penampilannya yang menarik sehingga dapat diterima oleh masyarakat.

Salah satu faktor yang mempengaruhi kestabilan adalah emulgator. ${ }^{4}$ Emulgator yang digunakan dalam formulasi lulur krim ini merupakan emulgator sintetik yang terdiri dari golongan anionik sabun amin, anionik detergen, dan nonionik karena dapat membentuk lapisan monomolekuler yang mampu menstabilkan emulsi dengan membentuk lapisan tunggal molekulmolekul atau ion-ion yang teradsorbsi pada antar muka emulsi minyak dalam air. $^{5}$

Berdasarkan hal tersebut di atas, maka telah dilakukan formulasi lulur krim dari yogurt dan beras hitam sebagai scrub dengan menggunakan variasi emulgator. Tujuan penelitian ini adalah untuk menghasilkan formulasi lulur krim yang stabil berdasarkan parameter organoleptis, volume kriming, viskositas, tipe aliran emulsi, homogenitas dan ukuran tetes terdispersi.

\section{METODE PENELITIAN}

\section{Bahan yang Digunakan}

Bahan-bahan yang digunakan adalah air suling, asam stearat, gliserin, metil paraben, natrium lauril sulfat, pati beras hitam, propil paraben, stearil alkohol, tween $80^{\circledR}$, triethanolamin, dan yogurt.

\section{Alat yang Digunakan}

Alat-alat yang digunakan adalah cawan porselin, alat gelas, konduktometri, lemari pendingin, pengaduk elektrik, penangas air, pipet volume, thermometer, timbangan analitik (AND) dan viskometer Brookfield.

\section{Rancangan Formula}

Formula lulur krim dirancang dengan menggunakan yogurt, asam stearat-trietanolamin, gliserin, metil paraben dan propil paraben, natrium lauril sulfat, pati beras hitam, stearil alkohol, pengental fase minyak, dan tween $80^{\circledR}$.

\section{Pembuatan Formula}

\section{Krim Lulur Dengan Emulgator Anionik Sabun Amin}

Ditimbang semua bahan sesuai dengan perhitungan, dibuat fase minyak dengan meleburkan asam stearat, propil paraben, dan stearil alkohol pada suhu $70^{\circ} \mathrm{C}$ diatas 
Formulasi Lulur Krim Yang Mengandung Kombinasi Yoghurt Dan Pati Beras Hitam ( sativa L.)

penangas air sambil diaduk. Dibuat fase air dengan melarutkan metil paraben dalam air panas pada suhu $70^{\circ} \mathrm{C}$. Ditambahkan gliserin, dan trietanolamin sambil terus diaduk. Selanjutnya dibuat emulsi dengan memasukkan fase minyak kedalam fase air sedikit demi sedikit kemudian diaduk dengan pengaduk elektrik hingga terbentuk emulsi sambil dilakukan pengocokan berselang selama 2 menit, ditambahkan yogurt dan diaduk lagi dengan pengaduk elektrik. Setelah itu ditambahkan pati beras hitam yang telah digerus dan diayak dengan ayakan mesh 30/40 lalu diaduk lagi hingga homogen.

\section{Krim Lulur Dengan Emulgator Nonionik}

Ditimbang semua bahan sesuai dengan perhitungan, dibuat fase minyak dengan meleburkan propil paraben, Asam stearat dan stearil alkohol pada suhu $70^{\circ} \mathrm{C}$ diatas penangas air sambil diaduk, dibuat fase air dengan melarutkan metil paraben dalam air panas pada suhu $70^{\circ} \mathrm{C}$. Ditambahkan gliserin dan tween $80^{\circledR}$. Setelah itu dibuat emulsi dengan memasukkan fase minyak kedalam fase air sedikit demi sedikit kemudian diaduk dengan pengaduk elektrik hingga terbentuk emulsi, sambil dilakukan pengocokan berselang selama 2 menit. Ditambahkan yogurt dan diaduk lagi dengan pengaduk elektrik. Ditambahkan pati beras hitam yang telah digerus dan diayak dengan ayakan mesh 30/40 lalu diaduk lagi hingga homogen.

\section{Krim Lulur dengan Emulgator Anionik Detergen}

Ditimbang semua bahan sesuai dengan perhitungan, dibuat fase minyak dengan meleburkan propil paraben, asam stearat dan stearil alkohol pada suhu $70^{\circ} \mathrm{C}$ diatas penangas air sambil diaduk, dibuat fase air dengan melarutkan metil paraben dalam air panas pada suhu $70^{\circ} \mathrm{C}$. Setelah itu ditambahkan gliserin dan natrium lauril sulfat. Dibuat emulsi dengan memasukkan fase minyak kedalam fase air sedikit demi sedikit kemudian diaduk dengan pengaduk elektrik hingga terbentuk emulsi, sambil dilakukan pengocokan berselang selama 2 menit. Selanjutnya ditambahkan yogurt dan diaduk lagi dengan pengaduk elektrik. Ditambahkan pati beras hitam yang telah digerus dan diayak dengan ayakan mesh 30/40 lalu diaduk lagi hingga homogen.

\section{Evaluasi Kestabilan Lulur Krim}

Evaluasi kestabilan lulur krim dilakukan sebelum dan sesudah penyimpanan dipercepat pada suhu 
Formulasi Lulur Krim Yang Mengandung Kombinasi Yoghurt Dan Pati Beras Hitam ( sativa L.)

$5^{\circ} \mathrm{C}$ dan $35^{\circ} \mathrm{C}$ secara bergantian masing-masing 12 jam selama 10 siklus. Parameter yang diukur adalah sebagai berikut:

\section{Pemeriksaan Organeoleptis}

Pemeriksaan organeoleptik meliputi warna, konsistensi dan bau sediaan lulur krim.

\section{Pengujian Homogenitas}

Pengujian homogenitas ini dilakukan dengan cara meletakkan sedikit krim diantara 2 kaca objek dan diperhatikan adanya partikel-partikel kasar atau ketidakhomogenan secara visual.

\section{Pengujian tipe emulsi}

Penentuan tipe emulsi dengan menggunakan metode hantaran listrik, yaitu emulsi yang telah dibuat dimasukkan sebanyak $25 \mathrm{ml}$ kedalam wadah kemudian diuji daya hantarnya dengan multimeter. Apabila jarum bergerak maka tipe emulsi adalah m/a dan sebaliknya apabila jarum tidak bergerak maka tipe emulsi yang terbentuk adalah $\mathrm{a} / \mathrm{m}$.

\section{Penentuan volume kriming}

Emulsi sebanyak $50 \mathrm{ml}$ ditempatkan dalam gelas ukur dan ditutup kemudian disimpan pada kondisi dipaksakan yaitu suhu $5^{\circ} \mathrm{C}$ dan $35^{\circ} \mathrm{C}$ secara bergantian masingmasing 12 jam. Kemudian diamati volume kriming yang terbentuk setiap satu siklus hingga siklus kesepuluh.

Pengukuran viskositas dan tipe aliran emulsi

Pengukuran dilakukan dengan menggunakan viskometer brokfield spindel no.64 dengan kecepatan 50 per menit (rpm) sedangkan penentuan tipe aliran emulsi dilakukan dengan mengukur viskositas sediaan pada berbagai kecepatan yaitu 2, 5, 10, 20, 30, 50 dan $100 \mathrm{rpm}$. Dari data tersebut dihitung kecepatan geser dan tekanan geser diplotkan membentuk rheogram untuk mengetahui tipe aliran yang terbentuk.

\section{Pengamatan tetes terdispersi}

Pengamatan dilakukan dengan meneteskan emulsi pada objek gelas, ditutup dengan deck glass. Selanjutnya diamati menggunakan mikroskop dengan pembesaran $40 \mathrm{x}$ 10.

\section{HASIL PENELITIAN}

Adapun hasil penelitian dari beberapa parameter kestabilan formulasi sediaan lulur krim yang mengandung kombinasi yogurt dan beras hitam dengan emulgator anionik sabun amin, emulgator nonionik, dan emulgator anionik detergen adalah sebagai berikut : 
Formulasi Lulur Krim Yang Mengandung Kombinasi Yoghurt Dan Pati Beras Hitam ( sativa L.)

\section{Pemeriksaan Organoleptik}

Tabel 1. Pemeriksaan Organoleptis Lulur Krim Sebelum dan Sesudah Kondisi Dipaksakan

\begin{tabular}{|c|c|c|c|}
\hline \multirow{2}{*}{ Sediaan } & \multicolumn{3}{|c|}{ Jenis Pemeriksaan } \\
\hline & Bau & Warna & Konsistensi \\
\hline \multirow{2}{*}{ Formula I } & Khas & Coklat & Kental \\
\hline & Khas & Coklat & Kental \\
\hline \multirow{2}{*}{ Formula II } & Khas & Coklat & Kental \\
\hline & Khas & Coklat & Kental \\
\hline \multirow{2}{*}{ Formula III } & Khas & Putih Kecoklatan & Kental \\
\hline & Khas & Putih Kecoklatan & Kental \\
\hline \multirow{2}{*}{ Formula IV } & Khas & Ungu & Kental \\
\hline & Khas & Ungu & Kental \\
\hline \multirow{2}{*}{ Formula V } & Khas & Ungu & Kental \\
\hline & Khas & Ungu & Kental \\
\hline \multirow{2}{*}{ Formula VI } & Khas & Putih Keunguan & Kental \\
\hline & Khas & Putih Keunguan & Kental \\
\hline \multirow{2}{*}{ Formula VII } & Khas & Ungu & Kental \\
\hline & Khas & Ungu & Kental \\
\hline \multirow{2}{*}{ Formula VIII } & Khas & Ungu & Kental \\
\hline & Khas & Ungu & Kental \\
\hline \multirow{2}{*}{ Formula IX } & Khas & Ungu & Kental \\
\hline & Khas & Ungu & Kental \\
\hline
\end{tabular}

\section{Keterangan :}

Formula I - III : Formula dengan emulgator anionik sabun amin

Formula IV - VI : Formula dengan emulgator nonionik

Formula VII - IX : Formula dengan emulgator anionik detergen

\section{Pengujian homogenitas}

Pengujian homogenitas

menunjukkan kesembilan sediaan Iulur

krim homogen karena menghasilkan sediaan yang bercampur dengan baik.

\section{Pengujian Tipe Emulsi}

Hasil pengujian tipe emulsi dari kesembilan formula menunjukkan lulur krim mempunyai tipe emulsi $\mathrm{m} / \mathrm{a}$ dan tidak terjadi perubahan sebelum dan sesudah kondisi dipaksakan.

\section{Pengamatan Volume Kriming}

Hasil pengamatan volume kriming pada penyimpanan dipercepat selama 10 siklus menunjukkan tidak adanya kriming yang terbentuk pada kesembilan formula. 
Formulasi Lulur Krim Yang Mengandung Kombinasi Yoghurt Dan Pati Beras Hitam ( sativa L.)

\section{Pengukuran Viskositas dan penentuan tipe aliran}

Tabel 2. Nilai Viskositas Lulur Krim Sebelum Dan Sesudah Kondisi Dipaksakan

\begin{tabular}{ccc}
\hline \multirow{2}{*}{ Formula } & \multicolumn{2}{c}{ Viskositas (P) } \\
\cline { 2 - 3 } & Sebelum & Sesudah \\
\hline I & 72,4 & 65,7 \\
III & 104,4 & 102,9 \\
IV & 96,2 & 99,0 \\
V & 65,8 & 62,0 \\
VI & 98,6 & 91,9 \\
VII & 78,5 & 71,8 \\
VIII & 60,5 & 65,1 \\
IX & 54,9 & 54,93 \\
\hline
\end{tabular}

Tabel 3. Nilai Yield Lulur Krim yang mengandung kombinasi yoghurt dan pati beras hitam sebagai scrub sebelum dan sesudah penyimpanan dipercepat

\begin{tabular}{ccc}
\hline \multirow{2}{*}{ Formula } & \multicolumn{2}{c}{ Nilai Yield } \\
\cline { 2 - 3 } & Sebelum & Sesudah \\
\hline II & 32,29 & 23,23 \\
III & 32,38 & 28,23 \\
IV & 37,49 & 31,79 \\
V & 29,44 & 22,96 \\
VI & 36,25 & 30,13 \\
VII & 41,45 & 32,11 \\
VIII & 23,34 & 33,38 \\
IX & 21,85 & 22,10 \\
\end{tabular}

\section{Pengamatan Tetes Terdispersi}

Pengamatan tetes terdispersi

dilakukan sebelum dan sesudah kondisi dipaksakan sehingga formula VII memiliki kestabilan yang paling optimal.

\section{PEMBAHASAN}

Formulasi sediaan lulur krim yang mengandung kombinasi yogurt dan pati beras hitam sebagai scrub dengan menggunakan variasi emulgator dan variasi konsentrasi 
Formulasi Lulur Krim Yang Mengandung Kombinasi Yoghurt Dan Pati Beras Hitam ( sativa L.)

emulgator dibuat sebanyak sembilan formula yakni lulur krim dengan emulgator anionik yaitu emulgator sabun amin menggunakan asam stearat dan trietanolamin dengan konsentrasi 4\% : 2\% (formula lulur krim I), emulgator sabun amin menggunakan asam stearat dan trietanolamin dengan konsentrasi $6 \%$ : $3 \%$ (formula lulur krim II), emulgator sabun amin menggunakan asam stearat dan trietanolamin dengan konsentrasi 8\% : 4\% (formula lulur krim III), lulur krim dengan emulgator nonionik menggunakan tween $80^{\circledR}$ dengan konsentrasi 3\% (formula lulur krim IV), emulgator nonionik menggunakan tween $80^{\circledR}$ dengan konsentrasi 4\% (formula lulur krim V), emulgator nonionik menggunakan tween $80^{\circledR}$ dengan konsentrasi 5\% (formula lulur krim VI), lulur krim menggunakan emulgator anionik yaitu emulgator detergen menggunakan natrium lauril sulfat dengan konsentrasi $0,25 \%$ (formula lulur krim VII), emulgator detergen menggunakan natrium lauril sulfat dengan konsentrasi $0,30 \%$ (formula lulur krim VIII), dan emulgator detergen menggunakan natrium lauril sulfat dengan konsentrasi $0,35 \%$ (formula lulur krim IX).

Setelah sediaan tersebut jadi maka dilanjutkan dengan pengujian kestabilan dengan mengukur beberapa parameter fisika baik kondisi sebelum dan sesudah penyimpanan dipercepat, yaitu pengamatan organoleptis, pengujian homogenitas, pengujian tipe emulsi, pengukuran volume kriming, pengukuran viskositas, penentuan nilai yield dan tipe aliran. Pengujian kestabilan dilakukan dengan kondisi dipaksakan yaitu penyimpanan pada suhu $5^{\circ} \mathrm{C}$ dan $35^{\circ} \mathrm{C}$ selama 10 siklus, masing-masing siklus berdurasi 12 jam. Tujuan dilakukannya kondisi dipaksakan adalah untuk mempercepat proses peruraian dari bahan-bahan dan untuk mempersingkat waktu pengujian.

Kestabilan dari sediaan lulur krim dievaluasi dengan menggunakan beberapa parameter pengujian yaitu sebagai berikut :

\section{Pengamatan Organoleptik}

Pengamatan organoleptik bertujuan untuk mengetahui ada tidaknya perubahan warna dan bau sebelum dan sesudah dilakukan kondisi dipaksakan. Dari hasil pengujian diperoleh bahwa kesembilan sediaan lulur krim tersebut stabil secara fisik. Hal ini menunjukkan bahwa tidak ada interaksi baik antara emulgator, bahan peningkat viskositas atau bahan tambahan lainnya. 
Formulasi Lulur Krim Yang Mengandung Kombinasi Yoghurt Dan Pati Beras Hitam ( sativa L.)

\section{Pengujian Homogenitas}

Pada pengujian homogenitas yang dilakukan dengan meletakkan sediaan lulur krim diantara 2 kaca objek diperoleh bahwa kesembilan sediaan lulur krim homogen karena menghasilkan sediaan yang bercampur dengan baik. Berdasarkan parameter ini kesembilan formula stabil.

\section{Pengujian Tipe Emulsi}

Pada pengujian tipe emulsi, uji dilakukan dengan hantaran listrik. Formulasi sediaan lulur krim yang mengandung kombinasi yogurt dan pati beras hitam sebagai scrub terbukti dapat menghantarkan arus listrik. Ini sesuai dengan teori yang menyatakan bahwa fase yang jumlahnya lebih besar pada umumnya akan menjadi fase luar (air). Diketahui bahwa air memiliki daya hantar listrik karena adanya ion-ion dalam air, sedangkan minyak tidak. Emulsi yang terbentuk merupakan emulsi m/a. Sehingga dapat disimpulkan bahwa kesembilan formula stabil pada pengujian tipe emulsi.

\section{Pengukuran Volume Kriming}

Pengamatan volume kriming sebelum dan sesudah penyimpanan dipercepat, pada formula I, II, III, IV, V, VI, VII, VIII, dan IX tidak menunjukkan adanya kriming. Hal ini disebabkan karena emulgator yang digunakan pada masing-masing formula membentuk lapisan yang liat disekeliling globul-globul terdispersi sehingga dapat disimpulkan bahwa kesembilan formula stabil berdasarkan parameter ini.

\section{Viskositas, Tipe Aliran dan Nilai Yield}

Viskositas sediaan diukur menggunakan spindle no.64 dengan kecepatan 50 rpm sebanyak tiga kali replikasi. Dari hasil pengukuran viskositas diperoleh hasil terdapat perbedaan yang nyata jika emulgatornya berbeda (analisis statistik ANOVA taraf kepercayaan 5\%). Hal ini diakibatkan karena adanya perbedaan variasi emulgator yang digunakan. Sedangkan berdasarkan perbedaan kondisi yaitu viskositas sebelum dan sesudah kondisi dipaksakan diperoleh hasil yang berbeda pada formula IV - VI yaitu yang menggunakan emulgator nonionik, tetapi pada formula I - III dan VI - IX tidak berbeda nyata. Sehingga dapat disimpulkan formula I - III dan VI - IX yang menggunakan emulgator sabun amin dan detergen menghasilkan lulur krim yang lebih stabil.

Tipe aliran suatu emulsi ditentukan oleh reogram yang 
Formulasi Lulur Krim Yang Mengandung Kombinasi Yoghurt Dan Pati Beras Hitam ( sativa $L$.)

terbentuk. Reogram kesembilan formula menunjukkan aliran plastis.

\section{Pengamatan Tetes Terdispersi}

Berdasarkan teori kualitas suatu emulsi didefenisikan bahwa emulsi yang mempunyai tetes terdispersi yang lebih halus dan memiliki ukuran partikel yang kecil akan mempunyai kualitas yang lebih baik. Maka dapat disimpulkan bahwa pada pengujian pengamatan tetes terdispersi formula VII memiliki kestabilan yang paling optimal.

\section{KESIMPULAN}

Berdasarkan hasil penelitian dan pembahasan serta pengolahan data statistik, maka disimpulkan bahwa kesembilan formula stabil, namun formula yang menggunakan emulgator anionik sabun amin (TEAStearat) dan detergen (natrium lauryl sulfat) memiliki kestabilan yang optimal dan sifat farmaseutik yang lebih baik.

\section{DAFTAR PUSTAKA}

1. Surajudin, Kusuma FR. Yoghurt Susu Fermentasi yang Menyehatkan. Jakarta : Agromedia Pustaka, 2005.

2. Jung, Wee $\mathrm{Y}$, et all., Biotechnological Production of Lactic Acid and Its Recent Applications. Republic of Korea : Departement of Material Chemical and Biochemical Engineering, Chonnam National University, Gwangju, 2006.

3. Ratnaningsih, Nani. Ringkasan Potensi Beras Hitam Sebagai Sumber Antosianin dan Aplikasinya Pada Makanan Tradisional Yogyakarta. Bogor : Balai Besar Penelitian dan Pengembangan Bioteknologi Sumberdaya Genetik Pertanian, 2010.

4. Jan W, Gooch. Encyclopedic Dictionary of Polymers $2^{\text {nd }}$ Edition. USA : Springer, 2010.

5. Gennaro R, Alfonso. Remington's Pharmaceutical Sciences $18^{\text {th }}$ edition. Marck Publishing Company, Easton: Pennsylvania, 1990. 